\title{
La ociosa suspicacia del cuentero: Manuel Ramos Otero
}

\section{Suspicions about the Idle Storyteller: Manuel Ramos Otero}

\author{
GISELLE ROMÁN MEDINAa \\ ${ }^{a}$ Pontificia Universidad Católica de Valparaíso, Instituto de literatura y ciencias del lenguaje. Chile. \\ Correo electrónico: giselle.roman@pucv.cl
}

De cara a una generalizada percepción de falta de tiempo libre en el presente orden neoliberal, este artículo examina las sospechas ante el ocio en "Vivir del cuento" (1987), de Manuel Ramos Otero. La investigación cultural, histórica y filosófica sobre el ocio ofrece numerosos ejemplos de su reprobación e incluso criminalización, sobre todo, en contextos de colonialidad. Tomo como puntos de partida tanto los discursos imperialistas que proyectan al Caribe como lugar de vagancia, a la vez que ocultan su historia de explotación, como sus rearticulaciones en discursos nacionalistas puertorriqueños. Con un enfoque en el producto literario, que Hannah Arendt clasifica como "trabajo", aunque inútil, identifico en Ramos Otero un cuestionamiento a la productividad como medio para la construcción de un programa político liberador, y una exploración del ocio como libre expresión.

Palabras claves: labor, trabajo, pereza, narración, colonialidad.

Engaging with a generalized perception of lack of free time exacerbated in the current neoliberal order, this article examines leisure/idleness (otium) in Manuel Ramos Otero's "Vivir del cuento" (1987). Scholarship about otium through a cultural, historical, and philosophical lens offers numerous examples of its censure, and even criminalization, in the contexts of coloniality or postcoloniality. I take as my starting point two intertwined views - the production of the Caribbean by imperialistic discourses as a place of "laziness" versus its history of exploitation-as well as the rearticulations in Puerto Rican national discourses of this suspicion about the alleged "vagancia" that affects the region. Focusing on the literary product, which Hannah Arendt classifies as "work", although it offers no "useful" product, I identify in Ramos Otero a questioning of productivity as a means of constructing a liberatory political program and the exploration of otium as free expression.

Key words: labor, work, laziness, storytelling, coloniality. 


\title{
1. El Desprecio al trabajo literario
}

\author{
Mister Noble nos mandó \\ A Hawai a trabajar. \\ Que no nos mandó a pasear. \\ Eso lo sabía yo. \\ Como estaba Puerto Rico \\ Que ahí los pobrecitos \\ No hayaban (sic) ganar el pan. \\ Y se tuvieron que marchar \\ A Hawai a prosperar. ${ }^{1}$
}

La administración del tiempo productivo e improductivo genera sospechas hacia y en el Caribe, con una particular atención a la producción literaria: "Ya no leo a nadie lo que escribo, ni dejo que lo lean pues lo que priva a esta isla no es admirar a uno porque escriba sino despreciarlo por envidia o por un sentido calvinista del deber y el trabajo. El que no se gana el pan con el sudor de una parte de su cuerpo no vale nada" (Ramos Otero 2002: 46). La cita anterior proviene de Página en blanco y staccato (1987 [2002]), de Manuel Ramos Otero (1948-1990), antología de cuentos donde se enfrenta la sospecha moralista hacia las actividades imaginativas, como la literaria, con la suspicacia crítica del trabajador de las palabras. En la cita, del cuento "La heredera", "Socorro Averasturi", escritora de la clase alta, presenta dos posibles explicaciones al alegado desprecio por la actividad literaria: "la envidia", la cual implica un privilegio y quizás un don, y el "sentido calvinista", la cual implica la injerencia religiosa, principalmente aquella cuyos valores se fortalecen con la presencia colonialista de los Estados Unidos en Puerto Rico. Queda la duda de si efectivamente se puede "ganar el pan" con lo que se escribe. De la queja de esta escritora privilegiada, aunque marginal en un canon literario patriarcal, resulta significativo no tanto la inversión de la jerarquía que coloca al trabajo intelectual por encima del físico, sino la contradicción del supuesto de que a su clase social se le permitiría escribir sin necesidad de justificarse. ${ }^{2}$ Si se trata de actividades en las que no se suda, letradas o imaginativas, tendrán que tener un propósito definido.

En otro de los relatos, "Vivir del cuento", se vuelve a manifestar ese recelo hacia la actividad literaria: "el público esperando una ponencia académica y lo único que del papel salía no lo era. El lugar era el bar de la esquina. Alguien en la primera fila comentó

\footnotetext{
${ }^{1}$ Citado por Carmen L. Torres-Robles.

${ }^{2}$ Si bien hay restos de esta jerarquía antigua que siguen operando hoy día, está lejos de operar con nitidez, ya que el valor de las actividades, sean físicas o intelectuales, está más que nunca condicionado por su rendimiento económico. Además, el trabajo frente al computador es en gran parte intelectual, si bien hay manos también en movimiento, y abarca una serie de operaciones de complejidad diversa y de desigual remuneración (Berardi 2009: 76).
} 
que la palabra no suda" (65). Se presume que la (no)ponencia del escritor "Manuel" trata sobre "Monserrate", labrador puertorriqueño que apenas sabía leer cuando entendió en un periódico hawaiano el estigma de "Porto Rican" debajo de la silueta dibujada de un criminal enmascarado" y de "vago" (52), esto era así pese a que junto a su mamá y padrastro conformaban "seis brazos de esclavos" (49). La ponencia trata también, en parte, sobre Liliuokalani, la reina hawaiana forzada a abdicar por el gobierno estadounidense, quien es comparada con Scheherezade por su habilidad para la fabulación y a la que "en Puerto Rico $[. .$.$] le hubieran gritado vaga cada vez que se atreviera a contarle un cuento a alguien"$ (64). ${ }^{3}$ Socorro -burguesa criolla-, Liliuokalani -realeza hawaiana-, Manuel -burgués criollo desclasado-y Monserrate -labrador pobre-, comparten el ser acusados de "vagos" por contar cuentos o "falsificar la realidad" (65). La preferencia por el término vago en el cuento, en lugar de perezoso, responde al hecho de que es más común en el habla puertorriqueña, pero, además, éste se refiere, por un lado, a lo indefinido, por el otro, a quien vaga o se desplaza. ${ }^{4}$ En dicho desplazamiento acumula las experiencias para sus cuentos, así como el narrador viajero al que se refería Walter Benjamin, solo que se lo priva de aprecio. En un bar, posiblemente ebria y con dificultad para pronunciar la " $n$ ", una de las amigas de Manuel, la poeta Vanessa, añade una arista que complejiza la acusación de vagancia: "Ese vive del cuemto,' 'ese es un cuemtista,' se le motea com desprecio y, al mismo tiempo, com fascinacióm por su capacidad para el imvemto, para el embuste, no hace nada, sólo cuemta. Vive y muere del cuemto. Es un paria amado y odiado" (sic) (65)..$^{5}$ La suspicacia hacia quien cuenta implica apreciaciones encontradas, correlacionales al posiblemente inútil rol del cuento. La acusación "no hace nada" confunde el carácter innecesario de la actividad literaria con la quietud. Contar cuentos, acreditan las voces del desdén, no se percibe como trabajo en una sociedad en la que se ha aprendido que ésa es la única actividad valiosa. Estas voces atestiguan una suerte de internalización del dogma de la productividad, producto de la ansiedad por controlar el tiempo libre, bajo sospecha de ser moralmente cuestionable, si no pecado o crimen. Una ideología conveniente para quienes, como la familia de Socorro, gozan de la plusvalía. Esa ideología, sin embargo, se vio que termina rebotándole a la misma heredera de la burguesía. Monserrate, quien, a diferencia de Socorro, Liliuokalani y el propio Manuel, siempre tuvo la necesidad de laburar con su cuerpo, es el personaje que con más contundencia perturba la noción del no sudor de las palabras, al darse el lujo de contar cuentos.

\footnotetext{
${ }^{3}$ Esto pese a que era una muy buena y cultivada narradora que capturaba a su audiencia: "se dice que Liliuokalani vivió del cuento [...] El cuento lo estaba contando la Schehrehzada que llevamos adentro [...] había leído los libros, los anales, las leyendas de los reyes antiguos [...] dicen que era muy elocuente y habladora y que daba gusto oírla contar cuentos interminables, a los que dedicaba toda su energía [...]" (64).

${ }^{4}$ A diferencia del perezoso, el vago puede ser a la vez vacuus (no trabaja), además de vagus (se traslada sin meta definida). Incluso si se trata de un vago-sedentario, la palabra vago connota exposición a la mirada, al afuera, al estar en la calle. Incluso si el vago se la pasa adentro de su casa, es observado y juzgado, no pasa por desapercibido.

${ }^{5}$ Como ya veremos, pudo haber dicho "cuentero" en lugar de "cuentista"; este uso a menudo intercambiable entre ambos, pese a que son palabras diferenciables, es clave.
} 
Si bien labor y trabajo se usan mayormente como sinónimos, la diferenciación entre estas dos actividades hecha por Hannah Arendt en La condición humana (1958[2005]) permite deslindar y pensar prácticas y espacios que tienen lugar en el cuento. La labor es definida por Arendt como la actividad que se hace con el cuerpo para satisfacer las necesidades que aseguran su supervivencia. En la distinción de Arendt, el trabajo, en contraste con la labor, es la actividad que deja algo para la posteridad y crea mundo, entendido como un espacio donde la vida humana, gracias al recuerdo y la permanencia, es posible más allá de su carácter meramente animal. ${ }^{6}$ En este deslinde, la actividad artística entra en la categoría del trabajo, si bien a diferencia de otras tareas artesanales, se caracteriza por su inutilidad y por facilitar el recuerdo de la acción política, el tercer ámbito de actividad deslindado, el cual es para Arendt el más humanamente admirable y sin duda único a los humanos. La actividad política, sólo posible una vez que se tienen cubiertas las necesidades vitales, consiste en actuar -y la palabra, dicha en el momento preciso, también es acción-y poner incluso la vida en riesgo. Ese actuar es la única forma en que se manifiesta la libertad (pública), pero es tan efímero como la labor, a no ser por el trabajo que lo pone por escrito o que lo hace arte permitiendo su recuerdo e incorporación al mundo. El arte se separa, pero a la vez se abre a la actividad política. Con la preponderancia de la necesidad y del utilitarismo que caracteriza a la edad moderna, una reacción que invirtió el lugar privilegiado que se le había dado a la contemplación -como quietud- a partir de Sócrates, la lógica de la labor coloniza a todas las actividades, y se convierte en justificativo del actuar. El marcado contraste entre skhole -o quietud, imperfectamente traducido al latín como otium, y ocio al español- y acción, se correlaciona al colapso entre los deslindes de la vida activa, que separaban labor, trabajo y acción política, convirtiéndose lo necesario o, por lo menos, lo útil, en requisito de toda actividad validada. ${ }^{7}$

A más de medio siglo de la publicación del libro de Arendt, el panorama se ha complejizado con las transformaciones de la producción postfordista, la informática, y la comodificación de toda actividad, al punto de que no importa su grado de abstracción o cuánto pueda parecerse al arte, es útil -e incluso necesaria- en la medida en que produzca ganancias. ${ }^{8}$ Estos cambios producen nuevas percepciones y temas de debate sobre la

\footnotetext{
${ }^{6}$ Esta diferenciación que toma Arendt de la antigüedad griega pre-socrática, le permite pensar las transformaciones que tienen lugar a lo largo de la historia occidental, y sobre todo en la edad moderna. Los valores, jerarquías y deslindes de la labor, el trabajo y la acción cambian a lo largo de la historia occidental (ni siquiera son estables durante toda la antigüedad, época en la que Arendt basa su deslinde). Arendt afirma que, con la emancipación de la labor, se dispara el consumo (de manera que los objetos se fabrican para no durar, no construyen mundo); la repetición dentro de las fábricas tiene mucho menos de trabajo, del cual la artesanía es un ejemplo, que de servicio que se desgasta en el acto, como la labor.

${ }^{7}$ Skhole-contemplación filosófica- se traduce como ocio trayendo muchas confusiones, pues agrega un sentido de consumo del tiempo libre alienante, por ejemplo, ese tiempo ocupado en ir al circo romano. Ver Rodrigo Elizalde y Christianne Gomes.

${ }^{8}$ En un mundo donde el mercado capitalista y el neoliberalismo son hegemónicos, se hace más difícil que nunca deslindar el tiempo productivo del improductivo. Libertad es una palabra manida por el neoliberalismo, que se
} 
actividad literaria y artística, en la que muchos depositaron funciones sociales utópicas que conllevaban a menudo una serie de pautas prefabricadas que no siempre convencieron a todos. ${ }^{9}$ Pregunto en este ensayo: ¿̨ómo la historia de la percepción de la actividad imaginativa es tratada en la escritura de Ramos Otero? ¿Cómo esta actividad imaginativa, que incluye tanto al echar cuento, como a la literatura, en Puerto Rico ha tenido una percepción historizable que pasa de la sospecha moralista anterior al neoliberalismo, a la emergencia de una subjetividad hegemónica neoliberal del rendimiento? La respuesta estética de Ramos Otero a esa pregunta, que se ampliará a continuación, es sospechar de la sospecha.

\section{Cuentista o cuentera/o}

Si en la distinción de Arendt entre labor y trabajo, la primera es la que está más atada a la sobrevivencia, se labura porque si no se muere, llama la atención que para "Vanessa" "se vive y se muere del cuemto". ¿Queda desplazado el trabajo literario en los ámbitos jerárquicos de la vida activa, acercándoselo a la labor, para que así sea valorado en una sociedad que estima por encima de todo lo necesario o, por lo menos, lo útil? O, por el contrario, ¿no es morir por el cuento una hazańa política, una elevada actividad humana? Las percepciones sobre la actividad literaria se articulan en Ramos Otero, en una estructura narrativa que deslinda espacios, campos de acción y personajes, para luego proceder al cruce, desplazamiento o colapso de los mismos, visibilizándose la inestabilidad-estable de las clases sociales. Por inestabilidad me refiero a los traslados y cambios a los que obliga el capitalismo colonialista, por estabilidad, a la pobreza que se mantiene. Acceder a los materiales del cuento, formas "menores" y "femeninas", cartas, rumores y conversaciones ajenas que son escuchadas por casualidad (no tan causal, con atenta intención), involucra el cruce de ámbitos (labor, trabajo, acción e, incluso, ocio) y el desprecio/aprecio hacia la actividad de contar. El cuentero, acusado de vago, oximonórico practicante de la noactividad, es quien pone a circular esos materiales.

Me detendré en el citado "Vivir del cuento", intento -¿fallido?- de ponencia de productividad académica sobre el trabajo literario y la labor del labrador-cuentero o del migrante-jornalero. "Cuentero" es la forma en que se nombra al propio Manuel, autofiguración de Ramos Otero, y a otros personajes, entre los que destaco a Monserrate. Es preciso ampliar qué se entiende generalmente por "cuentero" y por "vivir del cuento" para apreciar el alcance de su conexión con las acusaciones de vagancia que se leyeron en las

enarbola como justificación que deja en las sombras el propósito verdadero de este sistema, que consiste, para David Harvey, en la restauración y fortalecimiento del poder de clase.

${ }^{9}$ La literatura produce, claro está, pero el paso de presentarla como producción a adjudicarle una función o utilidad se da apresuradamente justamente por lo que Arendt presentaría como las consecuencias de la lógica de la labor invadiendo todos los ámbitos. En estos debates, es destacable la hipótesis que postula que la idea vanguardista de llevar el arte a la praxis fue realizada distópicamente por el mercado y la estetización de las mercancías. 
citas anteriores. De acuerdo con el diccionario oficial y los foros de discusión léxica, un cuentero es un sujeto que ejerce su capacidad imaginativa para la fabulación y la mentira. La expresión vivir del cuento sin duda se relaciona con la práctica del cuentero, en la medida en que la misma también gira entorno a la mentira o al engaño. Un primer acercamiento indica que vive del cuento la persona que cuenta historias con el propósito de obtener algún beneficio que va desde lograr ser admirado, hasta ganarse la vida sin trabajar; sin embargo, a menudo, se trata de sobrevivir.

Cabe preguntarse si el cuentero es interesado y deshonesto, si no cuenta solo por contar, lo que, de ser así, juzgárselo negativamente implicaría un remanente de una valoración antigua que entra en contradicción con la lógica del mercado. De esta duda se desprende otra, es decir, si no es más bien al revés, y que el cuentista, al hacer del contar su profesión, es el interesado que busca los efectos gratificantes del status que puede generar la admiración. ¿ O busca algo más noble: la inmortalidad? El ser prejuzgado de deshonesto coloca a quien vive del cuento en la posición de victimario. Sin embargo, dicho prejuicio se complica al considerarse que el cuentero puede vivir del cuento al contarse el cuento a sí mismo. Es así como la expresión también pasa a ser sinónimo de vivir de ilusiones, y de no hacer nada útil ni siquiera que le valga a sí mismo, lo que podría juzgarse peor que engañar para beneficio propio, si ese juicio se hace desde la lógica productivista que ha devenido en mera sanción de la acumulación de riquezas, lo que sucede sin duda por medios éticamente cuestionables. ${ }^{10}$ Paradójicamente, el cuentero, listo, pillo, victimario, pasa a ser iluso, robado, víctima. Por esto, rodea al cuentero un halo de sospecha, en resumen, porque parecería dedicar sus capacidades a un fin no productivo, a un fin parasitario: convencer a otros, mediante el manejo hábil de la palabra, para no trabajar, o convencerse a sí mismo de que puede vivir de tareas poco rentables o imposibles, o de la no tarea, es decir, de contar sin propósito. La sospecha, que desemboca a menudo en la criminalización del cuentero es similar, si no la misma, a la que se ha aplicado a las clases más pobres -"que si vivíamos de asistencia pública" dice Monserrate que se decía (61)-, si están dedicados a no hacer nada productivo, definición que es altamente subjetiva y dependiente del contexto y el sujeto que la hace. ${ }^{11}$ Por otra parte, el cuentero ocupa una posición informal y subordinada frente

\footnotetext{
${ }^{10}$ Para una discusión informal sobre los usos de la expresión "vivir del cuento", ver https://forum.wordreference. com/threads/vivir-del-cuento.398667l. Resulta relevante para esta discusión el vínculo establecido con la migración en el siguiente testimonio: "Yo también tuve que irme de mi país para sobrevivir. Estuve unos años trabajando en la Confederación Helvética... Suiza, para los no leídos... Claro que yo era mano de obra cualificada. Que eso es lo que os pasa, que venís aquí sin tener estudios, sin tener nada. Y claro, del cuento no se puede vivir". El comentario presume que se migra porque se persigue un cuento, una ilusión (para muchos, el sueño americano), para sobrevivir; pero si no se tiene la suficiente preparación, entonces, solo se vive del cuento sin que la realidad cambie o se produzca un ascenso social.

${ }^{11}$ La siguiente cita explica la sospecha que genera el ocio del pobre: "A laboring class person may be very busily engaged in activity, but if that activity brings reward only to him, it is idleness. [...] The third idea which I think is behind the definition of laboring-class idleness is that the poor must work with their bodies; mental labor, when engaged in by the poor, is not labor at all, but idleness" (Sarah Jordan 2003: 38-39). Por otra parte,
} 
al cuentista. El mismo sufijo -ero, si bien tanto como el de -ista, se utiliza a menudo para las profesiones, apunta más a una "condición moral". El diccionario de la RAE, al ofrecer ejemplos de ese uso del sufijo como condición moral, solo muestra adjetivos típicamente negativos: "altanero, embustero, traicionero", con la cual la mera morfología de la palabra predispone a la sospecha. Finalmente, podemos también considerar lo que dice la escritora Vanessa Droz, ficcionalizada en el relato de Ramos Otero, en un artículo publicado en 1983, donde hace explícito que ambos intentan vivir de la literatura y hacerla su oficio, lo cual perciben como una tarea difícil y no valorado por la sociedad. Asimismo, quizás no sea solo una coincidencia que Ramos Otero, quien también se dedicaba al performance, concibe su literatura como acto: 'la suprema vigilancia de las palabras nos hace asumir la responsabilidad en el acto' (1990: 10B). Esto lo acerca al concepto de acción definido por Arendt en la medida en que en su actuación se exponía a la no aceptación e irrumpía en contra de las normas de un público conservador.

En "Vivir del cuento" se le impone al cuentero más protagónico del relato, a Monserrate, el deber de producir la historia de su vida, de contar su "caso" por decirlo con el vocabulario de la picaresca, género del que participa el relato: "Me han preguntado muchas veces si me siento puertorriqueño y siempre he dicho que sí; pero, aunque no quisiera serlo no creo que me hubieran dejado olvidarlo. Hoy desde que llegué a Hawaii he aprendido a sentirme hawaiano: nos iguala la miseria" (Ramos Otero 2002: 57). El valor de la respuesta de Monserrate parece estar predeterminado y en dependencia de satisfacer las expectativas de quien pregunta. El cuentero lo sabe y complace a la audiencia con un sí, pero inmediatamente entrega un juicio en palabras que deshace a la respuesta automática. No depende tanto de su voluntad sentirse puertorriqueño, sino que se lo imponen como la tarea cansadora de la cual quizás querría descansar. Además, en la experiencia que ha ganado en sus traslados, ha aprendido que la internacional de la pobreza, de "la mudanza horizontal”, pesa más para él que la misma nacionalidad. El aquí y allá nacional pasa a ser una categoría menos parteaguas que el qué tienes y a qué te dedicas, si bien ambos también se condicionan por el espacio.

Para mostrar el cruce del borde que separa al ámbito del labrador del ámbito del cuentista, identificaré antes los deslindes entre las dos historias principales que le corresponden a cada uno. El cuento comienza con el relato de Monserrate:

Me llamo Monserrate Álvarez y nací en 1895, en un barrio de Manatí llamado La Florida que ahora me han dicho que es pueblo. Primero me jodieron por mestizo, después por puertorriqueńo, y luego por esa cuestión que llaman ciudadanía americana. En resumidas cuentas que siempre he estado jodido por pobre. De Puerto Rico no recuerdo nada excepto una quebrada, una finca de plátanos y

el cuentero criminalizado, al igual que el pobre criminalizado, aparece como víctima para Thorstein Veblen, para quien es la clase alta, que llama "leisure class", la que vive parasitariamente de las clases trabajadoras. Este panorama se complejiza hoy en día con una nueva clase caudalosa, producto del capitalismo financiero y tecnológico, que al parecer no cuenta con tiempo para el ocio. Ver Daniel Gross, "No Rest for the Wealthy". 
panapenes, unas sopas de guineas y cuatro hermanos que murieron de raquitismo, de paludismo, de lombrices. Hace más de treinta años que vivo aquí, en Molakai, con los leprosos (49).

Estas primeras líneas del cuento responden a la pregunta sobre su puertorriqueñidad antes citada y ejemplifican también el que no se la permiten olvidar. Monserrate nos presenta una versión abreviada y desinflada de su biografía, en la que curiosamente no dejan de marcarse las casillas de cualquier cuestionario de identidad oficial, constatándose nuevamente que, entre estas características, la pobreza, "en resumidas cuentas", es la más determinante para él. Coexisten dos explicaciones de ese "no creo que me hubieran dejado olvidarlo", interrelacionadas con lo que Sotomayor llama "la marca marginadora" de los personajes de Ramos Otero, quienes preferirían liberarse de ésta "para entrar en la humanidad plena" (1997: 140). Por un lado, sufre el discrimen hacia los puertorriqueños, por el otro, el mandato de encarnar la puertorriqueñidad articulado desde el nacionalismo como resistencia a la asimilación. Sus recuerdos sobre Puerto Rico son escasos y se resumen en naturaleza que produce alimento y en enfermedad que acelera el fin de la vida. Es decir, se presenta un ciclo de supervivencia en el cual el valor nutritivo de las "sopas de guinea" no es suficiente para superar la desnutrición, o el "raquitismo", de manera que la idealización de la isla como un paraíso de abundancia natural se rebate de entrada. Monserrate no es el migrante clásico nostálgico que idealiza la isla, pese a que su contexto se prestaría a dicha idealización ya que su destino no experimentó una mejora fuera de Puerto Rico. Aunque con la pobreza, "en resumidas cuentas", parecería explicar todo, Monserrate aceptará extender su biografía. De esta manera, complace a Manuel y a su amiga, también escritora, Magali.

El segundo cuento deslindado es el de Manuel, el escritor que nos relata la historia sobre cómo llegó a enterarse de la historia de Monserrate, la cual glosa, organiza y reacomoda:

No terminé de leer la carta. Monserrate Álvarez es el tipo de hombres que son personajes de cuento, de esquina y de barra. Además, las cartas siempre reconocen la presencia inmediata de un lector que está dispuesto a creer todo lo que le cuentan. Por otra parte, hablar de un puertorriqueño hawaiano precipita una sospecha de exotismo. La realidad, sin embargo, es mucho más compleja y no todo el mundo tiene los pies en la misma tierra (50).

Aquí nos enteramos de que la cita anterior a esta última, el comienzo, era una carta de Monserrate, y Manuel es su receptor, quien a lo largo de la narración intercalará otros fragmentos epistolares con su glosa. Manuel, cuentista de profesión, agrega un comentario reflexivo sobre el género epistolar para alertar sobre un pacto de lectura basado en la credulidad. La advertencia, sin embargo, rompe con el pacto. Manuel no es crédulo, nos invita a participar de su sospecha hacia el cuento, hacia el artificio exotista, y hacia el cuentero quien además "es personaje de cuento, de barra, de esquina", es decir, no es persona, sino ficción. Sin embargo, la mención de la presencia de Monserrate en la barra y 
en la esquina, lo vuelve materia reconocible más allá de la página, de ahí que "la realidad" sea "mucho más compleja". En otras palabras, se nos alerta sobre el talento de las personajes reales para la autoficcionalización, sobre todo tratándose de un individuo como Monserrate, es decir, un cuentero que ocupa su tiempo en la barra y en la esquina, contando historias de otros y de sí mismo, y "sin trabajar" (aunque ya sabemos que laburó desde nińo). La advertencia de Manuel, no obstante, puede ser leída como un intento de ganarse la confianza del lector, y establecer una alerta que desvía la atención. En otras palabras, al Manuel pedir que sospechemos de Monserrate, no puede evitar que el lector aprenda a sospechar también de él y de su propio cuento. Fue Manuel, después de todo, quien impulsó con sus preguntas la producción del relato del "puertorriqueño hawaiano".

Si bien Manuel glosa, selecciona y organiza la narración de Monserrate, al final de "Vivir del cuento" se vuelve evidente el colapso del límite que separaba los roles. Monserrate es ahora también el comentarista de una carta, la de Manuel/Magali, y elabora una crítica al referirse directamente a la actividad literaria de éstos:

Y entonces, de repente, llega una carta desde la colonia de Puerto Rico hasta la colonia de leprosos en Molokai devolviéndome de pronto la humanidad y ahora sí valgo como personaje de cuento, como trabajador inmigrante, como puertorriqueño, como leproso, y ya están revolcando la basura incoherente de mi historia para que esa tumba que todavía no reclama su inquilino reclame el epitafio que ustedes han escrito (68).

En este final se nos revela otro comienzo, la primera carta que recibe Monserrate, escrita por Manuel/Magali, enviada desde Puerto Rico -o Nueva York-, como un reclamo de historia. El comentario de Monserrate refleja conocimiento sobre el arte de narrar, por ejemplo, reconoce que su historia, entendida como un antes real, es incoherente y solo puede adquirir cualidad de relato una vez seleccionados y reorganizados sus elementos, proceso descrito con el verbo "revolcar", como si se escarbara entre la "basura", entre lo que sobra, para hallarse algunos elementos de valor. Se consolida el avance de Monserrate a la esfera del trabajo artístico, actúa como cuentista, a la vez que Manuel, al describir su relación con Magali, toma prestados el vocabulario y la experiencia de "la labor": "lo que más nos une es esa necesidad de vivir del cuento, de siempre estar pendiente a las conversaciones que cubren un tramo de acera en cualquier ciudad" (51). ${ }^{12}$ Paralelamente la

\footnotetext{
${ }^{12}$ Manuel y Magali se enteran de la existencia de Monserrate gracias a la atención a la conversación ajena, de Norma, estudiosa de la décima puertorriqueña en Hawaii. Esta es la condición de posibilidad de una historia cuyo archivo es oral. El cuentero puede ejercer gracias a que encuentra una audiencia de chismosos que lo escuchan. Curiosamente, el chismoso es el que cuenta chismes, pero es también el que los consume, gusta de ellos. El cuentero a su vez está pendiente de los chismes que elaborará en sus cuentos; esto ilumina a su vez, que al novelero/chismoso también se lo asocie con la improductividad, que a su vez sea condenado retóricamente, aunque se participe en su actividad. Sobre el novelero en la literatura puertorriqueńa -particularmente en las crónicas de Edgardo Rodríguez Juliá-, en relación al interés por la novedad, ver Giselle Román Medina.
} 
"historia invade", sus motivos, aparecen en otro espacio y viceversa, con lo cual, las fronteras entre el aquí y allá se vuelven menos determinantes (50). Estas conexiones entre los espacios se marcan, por ejemplo, con elementos que aparecen y reaparecen en Hawaii, New Jersey, New York, Puerto Rico, como la yautía que crece en Hawaii y se usa para hacer alcapurrias -comida puertorriqueńa-, el restaurante de mariscos en New Jersey y el padrastro pescador de Monserrate: "como si al haber trabajado esta tierra hubiéramos trabajado aquella tierra lejana, como si al pescar en este mar, pescáramos en esas otras playas" (63). Los traslados de estos elementos vuelven ubicuas a las señas de identidad, erigiéndose entonces un nuevo mundo tras éstos, ubicado en un bar llamado "Aqui me quedo" (64) -nótese que el nombre cancela el allá-.

Monserrate, ahora cuentista y “crítico", resalta la paradoja del género biográfico, el imperativo de poner un fin o cierre en la historia, porque la convención así lo pide, aun cuando la historia real, o la vida continúa, es matar a la persona para inmortalizarla. Se puede leer un reproche por parte de Monserrate, de que el modesto cambio en su vida, no el haber devenido cuentista sino el ser reivindicado, llega tarde. Las subalternidades de Monserrate ahora, en el cuento de Manuel, adquieren valor simbólico, como "personaje de cuento", si bien su pobreza se mantiene. La ficcionalización, que podría haber sido interpretada como un proceso deshumanizante en la medida en que la persona se transforma en personaje, curiosamente se presenta como una forma de restituir la humanidad, la vida contada, es la vida humana, se lo convierte en sujeto político. El orden verbal y la coherencia que permite es la que provee humanidad en el cuento, reconocer un mundo. Pero su historia tiene valor o es productiva si es la historia de un "trabajador inmigrante, como puertorriqueño".

Si quien vive del cuento es el cuentero, irónicamente, son Manuel y Magali a quienes se les puede aplicar la frase en cuanto a ganarse el pan con la profesión, de forma relativa, claro está, porque también se cuenta sobre cierta precariedad laboral de Manuel en varias instancias y otros relatos de la antología, sobre todo "Descuento". Además, se presume que se gana el pan como profesor y no propiamente como cuentista. Manuel, en efecto, es tratado como vago por la audiencia al presentar un cuento en lugar de una ponencia, por no hacer su trabajo. ${ }^{13}$ Como quien vive del cuento, cuentista profesional, se comporta en este marco como cuentero al intentar pasar gato por liebre, al esquivar la demanda de productividad de la institución. Al limarse las diferencias entre Monserrate, el cuentero, y Manuel/Magali, los cuentistas, lo que podría haberse interpretado como un vicio a veces y como una estafa otras, con ese desdén que reportaba Socorro, se presenta con ojos más empáticos, como una "necesidad", llevando la actividad del contar, entonces, al ámbito del sudor del cuerpo, de la labor. Esa necesidad y práctica del cuentista, intenta encontrar un espacio en los marcos institucionales, no solo porque le haga falta legitimarse, sino también porque le hace falta ganarse el pan en una sociedad que asimiló no valorar,

\footnotetext{
${ }^{13}$ Recordemos las palabras citadas al comienzo de este ensayo: "el público esperando una ponencia académica y lo único que del papel salía no lo era. El lugar era el bar de la esquina. Alguien en la primera fila comentó que la palabra no suda" (65).
} 
como vimos, al que no suda, aunque, esa asimilación esté sin duda llena de fisuras, entre ellas, la ambigua admiración al que cuenta.

La audiencia sospecha, está resentida, o bien porque se comporta como "cliente" del congreso, o bien como colega que sí tuvo que hacer el trabajo. Sin embargo, la expresión "la palabra no suda" delata un resentimiento que difícilmente podría haberse remediado con una ponencia académica, después de todo, también hecha de palabras. ¿̇ quién representa esa voz en la audiencia? Podría tratarse bien de un intelectual anti-intelectual, heredero de una retórica que llama a la acción, y que en teoría aprende o se inspira de la clase trabajadora que trabaja con el cuerpo o con otras partes de su cuerpo, además de la mente. Podría ser el resentimiento de quien sí trabaja con el cuerpo (porque no tiene otro remedio) o de quien más directamente se ha inspirado en el calvinismo. El resentimiento se esparce; aunque multifocal, es una manifestación del arraigo de la inversión de la jerarquía tradicional que situaba a la vida contemplativa por sobre la activa, característica de la edad moderna, que en lo religioso pone énfasis en las acciones en la tierra -el trabajar aquí como señal de haber sido elegido- y que se refleja en el modelo marxista al poner éste lo material por sobre el mundo de las ideas.

Favorecida la productividad hoy, la vida activa definida en cuanto a productora de riqueza, la acusación de pereza que marca el estigma tiene una función ciertamente productiva, para algunos. ${ }^{14} \mathrm{La}$ conveniencia de este discurso sobre la vagancia como justificativo de intervenciones imperialistas queda expuesta en el cuento a través de dos ejemplos de situación colonial que se conectan: "me enteré que el mismo año de 1898 cuando los Estados Unidos invadieron a Puerto Rico también se quedaron finalmente con Hawaii [...] Estos americanos han partido de verdad el mundo" (52). Se subrayan los intereses de la industria azucarera en Hawaii -siendo además la historia de la plantación tan determinante en el Caribe-, como el factor que motiva las invasiones y (fuerza) los traslados. La internacional colonial de la pobreza se expresa a partir de la imagen de la casa, un tropo de la literatura puertorriqueña:

Puerto Rico había sido una imagen, clara pero intocable, presente pero remota, y ese dolor y esa pobreza habían sido trasplantados a otro suelo y otra isla, como si el tiempo los hubiera obligado a pasar de un lado a otro del espejo, como si se hubieran mudado de casa y todavía tuvieran el mismo landlord (54).

Es decir, los puertorriqueños están privados de propiedad privada, bajo "orden de desahucio", y Monserrate, junto a los otros migrantes que van a parar a Hawaii, repite aspectos de la experiencia de la plantación (55). En la historia, las diferencias propiamente étnicas y nacionales pierden relevancia cuando se las compara en su horizontalidad, de colonia

\footnotetext{
${ }^{14}$ La acusación de pereza hacia las poblaciones no solo puertorriqueñas, sino caribeñas en general, es uno de los dispositivos retóricos más destacados del discurso colonialista en su afán por justificar la intervención imperial. Ver Albert Memmi, The Colonizer and the Colonized.
} 
a colonia, idea respaldada por el hecho de que el vicio de la vagancia se le adjudica tanto a los puertorriqueños como a los hawaianos. En el cuento, los dueños de las plantaciones aparecen, en efecto, como los confabuladores de la sospecha hacia la pereza, ayudados, claro está, por "el digno espíritu capitalista del protestantismo", cuya interrupción más potente es un ocio que lleva a imaginar otras alternativas de mundos pasados y futuros, y las acciones de resistencia de los migrantes por las que son criminalizados (58). Interrumpir la productividad, al igual que contar cuentos, se criminaliza porque atenta contra el orden impuesto, es decir, por su potencial político.

A leer la historia de Monserrate, en conexión con la de Liliuokalani, comparada con Scheherezade, se vuelve más evidente la idea de que para el sujeto subalterno, personajes femeninos colonizados o pobres, contar parece ser un modo de sobrevivir que, sin embargo, pone la vida en riesgo, es decir, exhibe la libertad del actuar. ${ }^{15}$ Por eso relatar la historia de Monserrate en Hawaii se plantea como un asunto de vida o muerte, vivir y morir del cuento, morirse por contarlo y contarlo por vivir. ${ }^{16}$ Como se vio hasta aquí, el ocio imaginativo del pobre y de la mujer -aquí desclasada - se criminaliza desde la lógica del protestantismo capitalista y desde la autoridad metropolitana. Sin embargo, ese prejuicio moralizante también reaparece en Puerto Rico, en boca de puertorriqueños. Esos puertorriqueños que se sienten muy atraídos al cuento de la cuentera o del cuentero y que a la vez los criminalizan y castigan, ¿quiénes son específicamente si aparecen de forma ubicua en varios sectores sociales? Desde luego, una lectura posible es atribuirles a los puertorriqueños una suerte de internalización del racismo, o de los valores de la metrópolis, al modo que explica Frantz Fanon, un auto-odio; o un auto-orientalismo o auto-tropicalismo. No obstante, el espíritu de la productividad, si bien cultivado y quizás radicalizado con la presencia colonialista de los Estados Unidos, se registra en las letras criollas de la isla, incluso desde antes de la invasión estadounidense. ${ }^{17}$ La sospecha hacia la vagancia es tanto de la metrópolis como

${ }^{15}$ En efecto la histórica reina hawaiana tejió una colcha durante su voluntario encierro tras firmar un tratado con los Estados Unidos. http://whip-stitch.com/the-queens-quilt/

${ }^{16}$ La comparación de Ramos Otero, empero, no entra en las posibles diferencias entre el "contar para sobrevivir" del lado de Hawaii y su estatus colonial, y del lado de Puerto Rico, donde el juglar europeo se mezcla con otras figuras del contar africano, también importante en el desarrollo de las tradiciones orales.

${ }^{17}$ Como demuestra Benigno Trigo, las autoridades españolas, bajo un argumento aún más de índole moral que el de índole pseudo-científica, habían prefigurado una patología de la sociedad puertorriqueña en las acusaciones de vagancia hacia ésta. El historiador puertorriqueño Salvador Brau, le da un giro al argumento, al responsabilizar en el siglo XIX a esa misma autoridad, concretamente a su mal gobierno, por los males isleños. Brau culpaba a las autoridades españolas del atraso de la isla, pero no dejó de aplicar una patologización selectiva de la sociedad puertorriqueña. Es decir, su argumento, des-patologizaba a los criollos y los presentaba como líderes naturales, a la vez que argumentaba que los negros, aunque percibidos como vigorosos, habían sido no obstante el agente patológico que enfermaba, generando indolencia, a las mujeres blancas pobres y éstas a toda la prole. Así legitimaba el rol de su clase para tomar las riendas del gobierno local que tan mal administraban los peninsulares. La administración estadounidense tras la invasión agrega a dicho fondo una intensificada patologización y criminalización de la pereza que se presenta entonces bajo argumentos pseudo-científicos. De la formación del canon nacional, se desprende que la escritura debe tener un función clara, de resistencia 
de la élite isleña. Y es a esa sospecha hacia la administración del tiempo productivo versus improductivo, a la que se le responde desde la suspicacia de la artesanía literaria, que permite deslindar y desarmar a la primera.

\section{LA LABOR DEL LETRADO PUERTORRIQUEÑO}

Las hipotéticas explicaciones de "Socorro" sobre el origen del alegado desprecio hacia la literatura, citadas al comienzo de este ensayo, tienen amplias resonancias históricas que incluyen a la pereza como pecado capital para las tradiciones judeocristianas, la moderna valoración de la acción por sobre la contemplación, la criminalización del ocio en las clases bajas en el contexto de la Revolución Industrial y los discursos imperialistas sobre ciertos climas y razas como naturalmente inclinados a tal vicio. La sospecha hacia el ocio, en el caso de Puerto Rico, se puede rastrear en un referente más cercano y específico al campo literario, es decir, el canon literario puertorriqueño. Para apreciar esta concatenación de resonancias, comenzaré por repasar la recepción de la obra de Ramos Otero, o dos recepciones, una que sospecha del autor y lo margina, y otra que sospecha con éste, con cuyas voces converso.

De acuerdo con críticos como Arnaldo Cruz Malavé, Jossianna Arroyo, Aurea Sotomayor y Juan Gelpí, la escritura literaria de Ramos Otero recibe en un comienzo una incómoda recepción en el campo literario puertorriqueño debido al acento en lo autobiográfico. Para Cruz Malavé, el yo de Ramos Otero, su declaración "la patria soy yo", representa un directo desafío al canon para el que, en palabras de Arroyo, lo primordial era satisfacer "la necesidad de construir una narrativa seminal y autorizada que conforme y defina la problemática de la identidad puertorriqueña" (304). Al Ramos Otero afirmar "La patria soy yo", "la familia soy yo", identifica un cuerpo singular, real, constatable, que el molde de familia impulsado por el canon letrado, pese a su apego a conceptos como Historia y Verdad, no representaba. Ramos Otero pone su propio cuerpo a la vista, en el centro, siendo éste el cuerpo marginal y patologizado por el canon.

En la siguiente cita de "Ficción e historia: texto y pretexto de la autobiografía" (una conferencia presentada en Nueva York en 1988), se puede notar que el yo del autor, se presentaba a sí mismo como cuentero, voz que en este marco podemos interpretar como no autorizada a hablar por la patria:

\footnotetext{
a la metrópolis y de articulación de lo nacional, masculina, de lo contrario se juzga inútil, junto a los vagos, borrachones, mujeres, a todos los que se les acusa de ser supersticiosos, e imaginativos, no precisamente en el buen sentido, a los que se le acusa de ser, para usar la palabras de Ramos Otero, "cuenteros". La figura masculina, del maestro que guía la escritura con un propósito ilustrador, pedagógico y político definido, es la verdaderamente productiva, pero no deja de ser heredera de estos discursos colonialistas, de reproducir una colonialidad del poder. Contra este panorama, donde se le exige un tipo de productividad particular a la literatura, una identidad prefabricada como modo de oponerse a los Estados Unidos, pero reproduciendo el dogma productivista que caracteriza los fundamentos de esta nación, es que se erige la figura del "cuentero".
} 
todo lo que escribo es un intento de atrapar, irónicamente, la voz de mi liberación, esa voz que al aprehender las otras voces de los otros cuenteros de la historia definirá mejor los bordes temporales de la lengua, ese órgano tan humano que lo mismo hace el amor con la piel polvorosa de otro cuerpo que con la piel polvorienta de la fábula. [...] Es curioso que los catálogos de nuestra lengua definen al cuentero además, como embustero (39-40).

La insistencia en el yo era entonces un gesto contra la norma, pese a que hoy en día, con su excesiva exhibición en las redes sociales, parezca a primera vista tener poco de subversivo. No obstante, el yo en Ramos Otero, observado en el conjunto de su obra, no solo se aprecia como subversivo cuando reconstruimos el contexto literario en que irrumpió, el contexto en el que se publicó la obra por primera vez. Mantiene el poder subversivo, por ejemplo, en lo que Ezequiel Zaidenwerg denomina anacronismo, refiriéndose a la poesía de Ramos Otero, y que define siguiendo a Elizabeth Freeman, como una forma de buscar en el pasado lo que pudo ser, la utopía y la resistencia a la lógica del mercado. Dicho anacronismo potencialmente revolucionario se encuentra también, argumento, en el homenaje a las décimas puertorriqueñas recopiladas en Hawaii, siendo la décima un género tan domesticado y oficializado. Esto es así porque siendo 'el género puertorriqueño por excelencia', pasa a ser, la materia del recuerdo y la experiencia en Hawaii. Zaidenwerg hace hincapié en diferenciar la nostalgia de la poesía de Ramos Otero, de aquella que es reaccionaria y la describe como "indecorosa". Tomando prestado el término, puede afirmarse que asumirse como cuentero va en contra del decoro. Ir contra el orden establecido, no tiene porque ser un inventar de cero, sino que se pueden recuperar en el pasado elementos con los que desestabilizar la hegemonía; por lo mismo, tampoco hay que asumir ingenuamente un carácter revolucionario de lo nuevo por nuevo, lo cual es reproducir la lógica del consumo sin experiencia.

Hay algo más que es importante subrayar y que se vio en el cuento a partir de las distintas voces de cuentistas y cuenteros que se encuentran, y es que ese yo cuentero en el que tanto insiste el escritor, tiene un componente colectivo, reconoce otras voces que lo potencian, que son también marginales y acusadas de improductivas. Acudir a las voces menores, y a géneros menores como las cartas, es escribir contra el decoro dictado por esa voz patriarcal, así como atender a la migración es escribir contra "la postulación nacionalista bipolar" del canon para el que la familia solo está en al isla (Sotomayor 137).$^{18}$ Ramos Otero, sin embargo, a diferencia de la voz patriarcal y autoritaria del canon, cuyo exponente más representativo es Antonio S. Pedreira, no pretende hablar por los demás y asume el riesgo de sus palabras. Esto no impide que dé crédito de las voces cuenteras que aprehende, a la vez que, como indica el verbo aprehender, hace explícito el mecanismo que posibilita

\footnotetext{
${ }^{18}$ En la lectura de Sotomayor sobre Ramos Otero se rastrea minuciosamente la genealogía alternativa a la historia, y a las obsesiones monumentales de la historia puertorriqueña y de su historia literaria. Se identifica, la sospecha sobre la evocación de las grandes categorías de la historia, la familia, la clase, la identidad, el sexo.
} 
liberar su propia lengua, y no la de todos. Hace explícito que no está representando a los otros cuenteros, sino aprendiendo de éstos. Para Ramos Otero su escritura es una expresión de libertad, pero la misma debe ser entendida no en un sentido romántico, sino como acto político, de un tipo compatible con la definición de Arendt, en la medida en que escribir abiertamente sobre su yo y su sexualidad, sin seguir las prerrogativas de lo que era escribir para "servir a la patria", supuso exponerse a críticas y arriesgar, o más bien no obtener, la estabilidad que le pudo haber garantizado un trabajo en Puerto Rico. Supuso también "sexiliarse". ${ }^{19}$ Ese acto de libertad que no nos promete una liberación colectiva, abre paso al presentar un modelo de liberación que cada uno tiene que jugarse desde su singularidad, con desafíos imprevistos.

El cuentero y, más aún, la cuentera, despierta sospechas por ser el foco de la ansiedad de la figura del pater familias que se propone controlar y administrar el ocio imaginativo con el fin productivo de estabilizar una identidad, de fijarla y definirla para que deje de ser vaga. Monserrate migra -o es migrado, siendo niño, junto a su familia, a su madre en realidad, pues su padre a cargo de educar y liderar el futuro, ¿por suerte?, abandona literalmente el barco-, y su desplazamiento para trabajar, como se vio, le gana irónicamente el mote de vago. La valoración de Monserrate como un inmigrante trabajador puertorriqueńo da cuenta de un cambio. Ese cambio no consiste tanto en que se lo valore como "trabajador" -lo que no iría contra un canon que condena la pereza-. Además, en las décadas siguientes el personaje trabajador se reivindica con más fuerza en la escritura de José Luis González, de formación marxista. El cambio se registra en su valoración como inmigrante, siendo esta figura marginal a la intelectualidad puertorriqueña aun en el momento que escribe Ramos Otero. Sin embargo, el cuentero levanta sospechas hacia esa reivindicación -ejemplificadas en la paradoja del vivir/morir, del epitafio de su muerte-, porque la misma demanda una historia definida, con un propósito, que podríamos definir como la representación del migrante puertorriqueńo. Ramos Otero, a través de Monserrate, invita a sospechar del empobrecimiento que puede experimentar el cuentero si es reificado, perdiendo así su potencial subversivo de vago. Pero esto no debe malinterpretarse como una celebración del no tener casa, del estar privado -sobre todo en un contexto de amplia expropiación sufrida por los puertorriqueños, que se repite en su historia-, sino del potencial de lo indefinido. Este es el espacio que se va achicando en esta etapa del neoliberalismo, y su exigencia de una productividad dentro del mercado, incluso también con el avance de políticas bien intencionadas, y necesarias, como las del affirmative action. Permiten hoy un espacio institucional para las sexualidades no heternormativas, para los migrantes puertorriqueños, para los sexiliados bajo el lema de la libertad, pero siempre y cuando se acojan a las nuevas definiciones del decoro, o lo correcto.

Vivir del cuento aparece como el atrevimiento a ser libre, aun cuando cubrir las necesidades, y la casa, no están garantizados. Asimismo, se trata del atrevimiento a dejar de

${ }^{19}$ La no heteronormatividad suponía vagancia para el canon, especialmente para René Marqués (Cruz Malavé). Sobre el sexilio de Ramos Otero, ver entrevista de Marithelma Costa. 
ser el cuerpo sin voz del puertorriqueño migrante trabajador en los Estados Unidos, que debía callar o bien hablar en inglés; del atrevimiento a vivir del cuento en español. En un mundo donde ya no hay una línea precisa que indique un afuera del mercado, el cuentero se enfrenta con el desafío de que esa etiqueta de trabajador inmigrante puertorriqueño, o la etiqueta que sea, no aplaste su vagar de cuentero o la práctica del ocio imaginativo, de la libre expresión. "La ponencia" rodea a esa búsqueda donde la palabra se acerca al sudor del cuerpo amado del relato artesanal, del artesano. Pretender que las palabras no solo den cuenta de los cuerpos que laburan y del sudor del goce sensual que, como la literatura, no produce (ni reproduce) nada útil, sino que además suden, con toda la ingenuidad del pillo, es vivir del cuento, un indecoroso pero honesto engaño.

\section{OBRAS CITADAS}

Arendt, Hannah. 2005. La condición humana. Barcelona: Paidós.

Arroyo, Jossianna. 1994. "Manuel Ramos Otero: las narrativas del cuerpo más allá de Insularismo”. Revista de estudios hispánicos 21: 303-324.

Benjamin, Walter. 1975. "El autor como productor". Tentativas sobre Brecht. Barcelona: Taurus.

Berardi, Franco. 2009. The Soul at Work. From Alienation to Autonomy. Los Ángeles: Semiotext (e).

Costa, Marithelma, y Manuel Ramos Otero. 1991. "Manuel Ramos Otero". Hispamérica 20.59: 59-67.

Cruz Malavé, Arnaldo. 1993. "Para virar al macho: La autobiografía como subversión en la cuentística de Manuel Ramos Otero". Revista iberoamericana 59.162: 239-263.

Droz, Vanessa. 1990. "Vivir del cuento". El Mundo. San Juan: 10 B.

Elizalde, Rodrigo y Christianne Gomes. 2010. "Ocio y recreación en América Latina: conceptos, abordajes y posibilidades de resignificación.” Polis. Revista Latinoamericana 26.

Gelpí, Juan. 1993. Literatura y paternalismo en Puerto Rico. San Juan: Editorial Universidad de Puerto Rico.

Gross, Daniel. 2009. "No Rest for the Wealthy". The New York Times.

Harvey, David. 2007. A brief history of neoliberalism. New York: Oxford University Press.

Jordan, Sarah. 2003. The Anxieties of Idleness: Idleness in Eighteenth-Century British Literature and Culture. Crandbury: Bucknell University Press.

Memmi, Albert. 2013. The colonizer and the colonized. Routledge.

Román Medina, Giselle. 2009. "Las tribulaciones de Jonás y El entierro de Cortijo de Edgardo Rodríguez Juliá: la novelería de la gran familia puertorriqueña." Bulletin of Spanish Studies 86.5: 675-689.

Ramos Otero, Manuel. 1990. "Ficción e historia: texto y pretexto de la autobiografía". El Mundo 14: 20-23. . 2002. Página en blanco y staccato. San Juan: Plaza Mayor. 
Sotomayor, Áurea María. 1997. "Genealogías o el suave desplazamiento de los orígenes en la narrativa de Manuel Ramos Otero". Iberoamericana (1977-2000) 21.3/4 (67/68): 133-155.

Torres-Robles, Carmen, L. 2004. "Boricuas en Hawai: identidad y expresión". Bilingual Review/La Revista Bilingüe, 28.1: 16-22.

Trigo, Benigno. 2000. Subjects of crisis: Race and gender as disease in Latin America. Wesleyan University Press.

Veblen, Thorstein. 1994. The Theory of the Leisure Class. Penguin Books.

Zaidenwerg, Ezequiel. 2017. "Indecoro, anacronismo, utopía: sobre la poesía de Manuel Ramos Otero”. Revista Hispánica Moderna 70.1: 77-95. 
